\title{
Aspects of activity behavior as a determinant of the physical activity level.
}

Citation for published version (APA):

Bonomi, A., Plasqui, G., Goris, A. H., \& Westerterp, K. R. (2012). Aspects of activity behavior as a determinant of the physical activity level. Scandinavian Journal of Medicine \& Science in Sports, 22(1), 139-145. https://doi.org/10.1111/j.1600-0838.2010.01130.x

Document status and date:

Published: 01/01/2012

DOI:

10.1111/j.1600-0838.2010.01130.x

Document Version:

Publisher's PDF, also known as Version of record

Document license:

Taverne

Please check the document version of this publication:

- A submitted manuscript is the version of the article upon submission and before peer-review. There can be important differences between the submitted version and the official published version of record.

People interested in the research are advised to contact the author for the final version of the publication, or visit the DOI to the publisher's website.

- The final author version and the galley proof are versions of the publication after peer review.

- The final published version features the final layout of the paper including the volume, issue and page numbers.

Link to publication

\footnotetext{
General rights rights.

- You may freely distribute the URL identifying the publication in the public portal. please follow below link for the End User Agreement:

www.umlib.nl/taverne-license

Take down policy

If you believe that this document breaches copyright please contact us at:

repository@maastrichtuniversity.nl

providing details and we will investigate your claim.
}

Copyright and moral rights for the publications made accessible in the public portal are retained by the authors and/or other copyright owners and it is a condition of accessing publications that users recognise and abide by the legal requirements associated with these

- Users may download and print one copy of any publication from the public portal for the purpose of private study or research.

- You may not further distribute the material or use it for any profit-making activity or commercial gain

If the publication is distributed under the terms of Article $25 \mathrm{fa}$ of the Dutch Copyright Act, indicated by the "Taverne" license above, 


\title{
Aspects of activity behavior as a determinant of the physical activity level
}

\author{
A. G. Bonomi ${ }^{1,2}$, G. Plasqui ${ }^{1}$, A. H. C. Goris ${ }^{3}$, K. R. Westerterp ${ }^{1}$ \\ ${ }^{1}$ Department of Human Biology, Maastricht University, Maastricht, The Netherlands, ${ }^{2}$ Group Care and Health Applications, Philips \\ Research Laboratories, Eindhoven, The Netherlands, ${ }^{3}$ Philips New Wellness Solutions, Lifestyle Incubator, Amsterdam, The \\ Netherlands \\ Corresponding author: Alberto G. Bonomi, Department of Human Biology, Maastricht University, PO Box 616,6200 MD \\ Maastricht, The Netherlands. +Tel: 003140 2748051, Fax: +003143 3670976, E-mail: a.bonomi@HB.unimaas.nl
}

Accepted for publication 3 February 2010

\begin{abstract}
This study investigated which aspects of the individuals' activity behavior determine the physical activity level (PAL). Habitual physical activity of 20 Dutch adults (age: 26-60 years, body mass index: $24.5 \pm 2.7 \mathrm{~kg} / \mathrm{m}^{2}$ ) was measured using a tri-axial accelerometer. Accelerometer output was used to identify the engagement in different types of daily activities with a classification tree algorithm. Activity behavior was described by the daily duration of sleeping, sedentary behavior (lying, sitting, and standing), walking, running, bicycling, and generic standing activities. Simultaneously, the total energy expenditure (TEE) was measured using doubly labeled water. PAL was calculated as TEE divided by sleeping metabolic rate. PAL was
\end{abstract}

significantly associated $(P<0.05)$ with sedentary time $(R=-0.72)$, and the duration of walking $(R=0.49)$, bicycling $(R=0.77)$, and active standing $(R=0.62)$. A negative association was observed between sedentary time and the duration of active standing $(R=-0.87 ; P<0.001)$. A multiple-linear regression analysis showed that $75 \%$ of the variance in PAL could be predicted by the duration of bicycling (Partial $R^{2}=59 \% ; P<0.01$ ), walking (Partial $\left.R^{2}=9 \% ; P<0.05\right)$ and being sedentary (Partial $R^{2}=7 \%$; $\boldsymbol{P}<0.05)$. In conclusion, there is objective evidence that sedentary time and activities related to transportation and commuting, such as walking and bicycling, contribute significantly to the average PAL.
Physical activity (PA) is frequently recommended to improve health and prevent chronic diseases (Blair et al., 2001; Kriska et al., 2003). Increasing the PA level (PAL) can reduce the risks associated with obesity and diabetes, such as hypertension, and cardiovascular diseases (Kesaniemi et al., 2001; Kriska et al., 2003). For this reason, in 1995, the World Health Organization and the Centers for Disease Control and Prevention (Pate et al., 1995) recommended the engagement in at least $30 \mathrm{~min}$ of moderate-intensity activity per day to promote and maintain health. A later revision of these guidelines emphasized the importance of combining moderate- and high-intensity activities to achieve a high activity level and gain health benefits (Haskell et al., 2007). Complementing these recommendations, decreasing sedentary behaviors has emerged as an important target for health promotion (Dietz, 1996; Epstein \& Roemmich, 2001). Indeed, the time spent in low-intensity activities has been associated with markers of obesity (Ekelund et al., 2008), weight gain ( $\mathrm{Hu}$ et al., 2003; Levine et al., 2008), and diabetes (Hu et al., 2003). Also, it has a negative impact on the PAL (Westerterp, 2001). Inspite of these guidelines, it still remains unclear whether the engagement in high-intensity PA significantly contributes to the PAL. High-intensity PA might discourage the engagement in other types of activities outside the exercise session, and persuade compensatory behaviors that tend to decrease the activity energy expenditure (Meijer et al., 1999; Westerterp, 2001). Therefore, understanding the role of the individuals' PA behavior in determining the PAL is essential to design effective intervention strategies to increase PA.

Habitual PA can objectively be assessed in daily life by recording body movements using activity monitors. These activity monitors, also called accelerometers, are considered to be the most convenient and most reliable tools to measure PA (Macfarlane et al., 2006). Recently, they have been used in combination with classification algorithms to identify specific human movements (Veltink et al., 1996; Pober et al., 2006; Ermes et al., 2008; Bonomi et al., 2009a, b; Preece et al., 2009). This classification of activity types is based on the evaluation of attributes (features) of the recorded acceleration of the body with machine learning algorithms. Some studies focused on measuring body movements with accelerometers positioned on different body parts to identify lying, sitting, standing, walking, and running activities, 


\section{Bonomi et al.}

using neural network algorithms for the activity classification (Zhang et al., 2003). Only recently, developments in activity monitoring allowed the recognition of several types of physical activities using a single waist-mounted accelerometer (Mathie et al., 2004; Karantonis et al., 2006; Bonomi et al., 2009a, b). This innovative methodology of analyzing accelerometer data can be used to specifically determine the PA behavior, by measuring the daily distribution of various types of activities.

The current study investigated the relationship between the PAL, as assessed using the gold standard technique of doubly labeled water, and the individuals' activity behavior. A novel technique based on a tri-axial accelerometer and a classification algorithm was used to objectively determine PA behavior, by measuring the daily engagement in different types of activities. The purpose was to analyze which types of PA such as sleeping, sedentary behavior (lying, sitting, and standing), generic standing activities (active standing), walking, bicycling, and running determined the PAL.

\section{Methods}

Subjects

Twenty healthy Dutch adults (11 men and nine women) were recruited by advertisement in local newspapers. The study was conducted during autumn, and most of the participants were living in the neighborhood or in the city of Maastricht, the Netherlands. The study was approved by the Ethics Committee of the Maastricht University Medical Center, and written informed consent was obtained from the participants.

\section{Study design}

Subjects reported to the laboratory on day 0 at 9:00 hours and entered a respiration chamber for an overnight stay. Anthropometric measurements were taken in the morning after an overnight fast. Body mass was measured on an electronic scale (Mettler Toledo ID1 Plus, Giessen, Germany) to the nearest $0.01 \mathrm{~kg}$. Height was measured to the nearest $0.1 \mathrm{~cm}$ (SECA Mod.220, Hamburg, Germany). PA was measured from the morning of day 1 until the morning of day 15. The total energy expenditure (TEE) and PAL were measured during an observation period of 2 weeks, from day 1 until day 15 .

\section{Energy expenditure and PAL}

TEE was measured using the doubly labeled water (DLW) method according to the Maastricht protocol (Westerterp et al., 1995). After the collection of a background urine sample, subjects drank on the evening of day 0 a weighted amount of ${ }^{2} \mathrm{H}_{2}^{18} \mathrm{O}$ such that baseline levels were increased to $100 \mathrm{ppm}$ for ${ }^{2} \mathrm{H}$ and to $200 \mathrm{ppm}$ for ${ }^{18} \mathrm{O}$. Additionally, urine samples were collected from the second voiding in the morning and a subsequent voiding in the evening of days 1,8 , and 15 . PAL was calculated as TEE divided by the sleeping metabolic rate (SMR). SMR was measured during an overnight stay in the respiration chamber. The room measured $14 \mathrm{~m}^{3}$ and was equipped with a bed, table, chair, freeze toilet, washing bowl, radio, television, and computer (Schoffelen et al., 1997).
Energy expenditure was calculated from $\mathrm{O}_{2}$-consumption and $\mathrm{CO}_{2}$ production according to Weir's (1949) formula. SMR was defined as the lowest observed energy expenditure for 3 consecutive hours during the night. Room temperature was held constant at $20 \pm 1{ }^{\circ} \mathrm{C}$.

\section{Monitoring of PA}

The motion sensor used was a modified version of the previously validated Tracmor (Philips Research, Eindhoven, the Netherlands) (Plasqui et al., 2005). The device included a triaxial accelerometer and recorded acceleration samples 20 times/s. The Tracmor measured $8 \times 3.5 \times 1 \mathrm{~cm}$ and weighed $34.8 \mathrm{~g}$, including the battery. The Tracmor was fixed at the lower back using an elastic belt. The $x-, y$-, z-axes of the accelerometer were oriented along the vertical, medio-lateral, and antero-posterior directions of the body, respectively. Subjects were instructed to wear the Tracmor during waking hours, except during showering and water activities. A diary was used to report periods in which the subject was sleeping and not wearing the Tracmor during the day. Furthermore, the diary was used by the subjects to self-report the duration of discrete bouts of spontaneous bicycling and running activities.

\section{Identification of activity type}

The raw acceleration signal was downloaded to a personal computer and processed to identify types of PA performed during the day. The acceleration signal was segmented in intervals of $6.4 \mathrm{~s}$ and features of the acceleration were determined for each axis of measurement, e.g. average, standard deviation, peak-to-peak distance, and dominant frequency in the power spectral density (Bonomi et al., 2009a). A classification tree algorithm was used to evaluate the features and to classify the acceleration in one of six activity classes: lying, sitting, or standing (sit-stand), active standing, walking, bicycling, and running. The active standing type was defined to represent dynamic activities not related to ambulation performed in the standing position. The classification tree was developed before the current study on a population characterized by a broad range of weight, height, and age: 37 men and 43 women, [mean \pm SD (minimum - maximum) $]$ weight $=78 \pm 20(51-182) \mathrm{kg}$, height $=1.72 \pm 0.1(1.49-1.97) \mathrm{m}$, age $=42 \pm 16(19-71)$ year, and $\mathrm{BM}$ index $(\mathrm{BMI})=26.2 \pm 5.8(19.2-53.9) \mathrm{kg} / \mathrm{m}^{2}$. The calibration was based on data collected during supervised tests. The acceleration measured during lying, sitting, standing, walking, running, bicycling, washing dishes and sweeping the floor was used to calibrate the decision tree. The data collected during the dishwashing and floor-sweeping activities were used to define the active standing category. The data collected during lying, sitting, and standing were used to define the sedentary category.

Classification trees are models in which the classification process is defined by a sequence of conditions based on features of the object to classify (Duda et al., 2000). Figure 1 shows the structure of the developed classification tree and the features selected for the identification of activity types. The performance of the classification tree is described elsewhere (Bonomi et al., 2009b).

\section{Data analysis and statistics}

Monitoring days of PA were considered valid if the nonwearing time, annotated in the diary, did not exceed $150 \mathrm{~min} /$ day. As a result, the average number of monitoring days was $8 \pm 5$ days (range: $3-14$ days). The non-wearing time was removed from the dataset and not used by the classification tree for the identification of activity types. For each subject, 


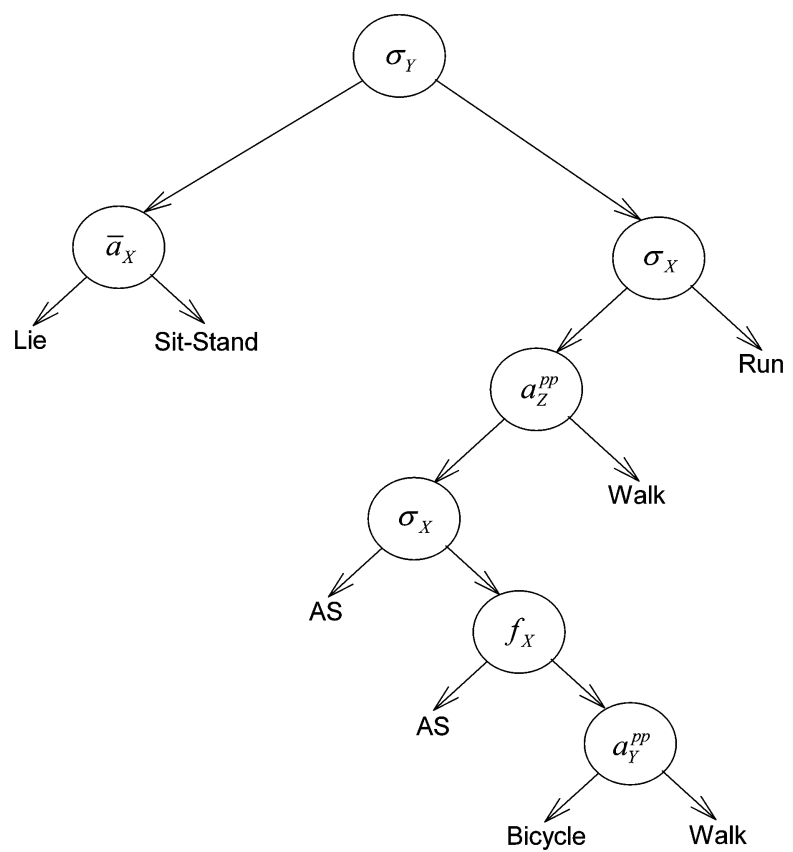

Fig. 1. Structure of the classification tree used to identify activity types. Circles represent conditions based on features of the acceleration signal. From the circles, branches depart and lead to a class that identifies the object to classify. The classes identified by the classification tree were: lying, sitting, and standing (sit-stand), active standing (AS), walking, running, and bicycling. The features used by the decision tree were: $\sigma_{X}, \sigma_{Y}$, standard deviation in the $x$ - and $y$-axis; $\bar{a}_{X}$, average acceleration in the $x$-axis; $f_{X}$, dominant frequency of the acceleration in the $x$-axis; $a_{Z}^{\mathrm{pp}}, a_{Y}^{\mathrm{pp}}$, peak-topeak distance of the acceleration in the $z$ - and $y$-axis. The $x-, y-, z$-axes correspond to the vertical, medio-lateral, and antero-posterior directions of the body, respectively.

PA behavior was defined by the average daily duration $\left(\mathrm{AD}_{\mathrm{D}}\right)$ of sleep, sedentary behavior, active standing, walking, bicycling, and running activity types. The time spent sleeping was determined by the diary annotations. The time spent being sedentary was determined by the sum of the duration of lying, sitting, and standing during waking hours. Simple regression analysis was used to examine the relationship between the PAL and $\mathrm{AD}_{\mathrm{D}}$ of each activity type. The Pearson correlation coefficient $(R)$ was calculated to determine the association between variables. Based on the PAL, subjects were divided into two groups: the highly active group ( ${ }^{\mathrm{HIGH} P A L}$; PAL $>1.75)$ and the less active group ( ${ }^{\text {LOW }}$ PAL; PAL $<1.75)$. This PAL value of 1.75 was used as threshold as it represented the average PAL of modern humans, which ranges from 1.5 to 2.0 (Black et al., 1996; Westerterp, 2008). The Student $t$-test was performed to identify significant differences in the PA behavior of subjects in the ${ }^{\text {LOW }} \mathrm{PAL}$ group compared with that of subjects in the ${ }^{\mathrm{HIGH}} \mathrm{PAL}$ group. The stepwise multiple-linear regression analysis was performed to select the best predictors of PAL among the types of activities that were used to characterize the individuals' behavior. As the daily duration of running was not normally distributed, this variable was log transformed. Cook's distance was calculated for each data point to identify influential cases that could impact the result of the regression analysis. All analyses were carried out using a Matlab statistical toolbox
(The MathWorks, Natick, Massachusetts, USA) and SigmaStat (Systat Software, San Jose, California, USA). Measured parameters are presented as average \pm standard deviation (SD). The statistical significance was set at $P<0.05$.

\section{Results}

The mean PAL was $1.77 \pm 0.17$ (Table 1). On average, PA was monitored for $14.4 \pm 1.1 \mathrm{~h} /$ day, which was $92.1 \pm 4.5 \%$ of the waking hours. The $\mathrm{AD}_{\mathrm{D}}$ of each activity type describing individuals' behavior is presented in Table 2. A high correlation was observed between reported (rep) and measured (m) $\mathrm{AD}_{\mathrm{D}}$ of bicycling (rep $=14.8 \pm 15.7 \mathrm{~min} /$ day vs $\mathrm{m}=22.1 \pm 14.9 \mathrm{~min} /$ day; $R=0.77, P<0.001)$ and running $\quad(\mathrm{rep}=2.1 \pm 4.9 \mathrm{~min} /$ day $\quad$ vs $\mathrm{m}=3.2 \pm$ $4.4 \mathrm{~min} /$ day; $R=0.81, \quad P<0.001)$. As shown in Fig. 2, sedentary activities occupied almost $29 \%$ of the day ( $42 \%$ of waking hours). As presented in Table 2, PAL was inversely related to the sedentary time, while it was positively associated with the $\mathrm{AD}_{\mathrm{D}}$ of active standing, walking, and bicycling. The relationship between PAL and $\mathrm{AD}_{\mathrm{D}}$ of running just failed to reach significance $(R=0.46, P=0.06)$. No significant relationship was observed between PAL and the time spent sleeping $(P=0.61)$. A strong negative correlation was observed between the $\mathrm{AD}_{\mathrm{D}}$ of active standing and sedentary time $(R=-0.87, P<0.001)$. No significant relationship was observed between the $\mathrm{AD}_{\mathrm{D}}$ of the other activity types.

Ten subjects (six males and four females; age: $43 \pm 12$ years; BMI: $24.4 \pm 2.8 \mathrm{~kg} / \mathrm{m}^{2}$ ) had a PAL $<$ 1.75 and were used to define the ${ }^{\text {LOW } P A L}$ group, while 10 subjects (five males and five females; age: $40 \pm 11$ years; BMI: $24.5 \pm 2.8 \mathrm{~kg} / \mathrm{m}^{2}$ ) had a PAL $>1.75$ and were included in the ${ }^{\mathrm{HIGH}} \mathrm{PAL}$ group. A significantly different PA behavior was observed between the ${ }^{\mathrm{HIGH}} \mathrm{PAL}$ and the ${ }^{\mathrm{LOW}} \mathrm{PAL}$ groups. As shown in Fig. 3, the ${ }^{\mathrm{HIGH}} \mathrm{PAL}$ group spent significantly less time being sedentary than the

Table 1. Subjects characteristics, $N=20$ (11 men; nine women)

\begin{tabular}{lcc}
\hline & Mean \pm SD & Range \\
\hline Age (year) & $41 \pm 11$ & $26-60$ \\
Height $(\mathrm{m})$ & $1.75 \pm 0.09$ & $1.57-1.89$ \\
Body mass $(\mathrm{kg})$ & $74.8 \pm 11.4$ & $54.5-103.4$ \\
BMl $\left(\mathrm{kg} / \mathrm{m}^{2}\right)$ & $24.5 \pm 2.7$ & $19.6-29.5$ \\
Fat mass $(\mathrm{kg})$ & $20.4 \pm 6.4$ & $8.4-33.2$ \\
Fat free mass $(\mathrm{kg})$ & $54.4 \pm 8.3$ & $39.4-70.2$ \\
SMR (MJ/day) & $6.9 \pm 0.8$ & $5.5-8.2$ \\
TEE (MJ/day) & $12.2 \pm 1.9$ & $9.6-15.5$ \\
AEE (MJ/day) & $4.1 \pm 1.2$ & $2.1-6.4$ \\
PAL & $1.77 \pm 0.17$ & $1.43-2.08$
\end{tabular}

BMI, body mass index; SMR, sleeping metabolic rate; TEE, total energy expenditure; AEE, activity energy expenditure; PAL, physical activity level (TEE/SMR). 


\section{Bonomi et al.}

${ }^{\text {LOW }}$ PAL group, and significantly more time actively standing, walking, and bicycling.

The stepwise multiple-linear regression analysis showed that the best predictors of PAL were the $\mathrm{AD}_{\mathrm{D}}$ of bicycling (Partial $R^{2}=59 \% ; P<0.01$ ), walking (Partial $R^{2}=9 \% ; P<0.05$ ), and the sedentary time (Partial $R^{2}=7 \% ; P<0.05$ ). The model explained $75 \%$ of the variance in PAL, and the coefficients of the multiple-linear model are presented in Table 3. The Cook's distance did not indicate any observation as being an outlier or having an intolerable influence on the result of the regressions (distance $<0.2)$.

\section{Discussion}

To our knowledge, this is the first study to report on a relation between the daily activity behavior and the PAL as measured using DLW. The results showed

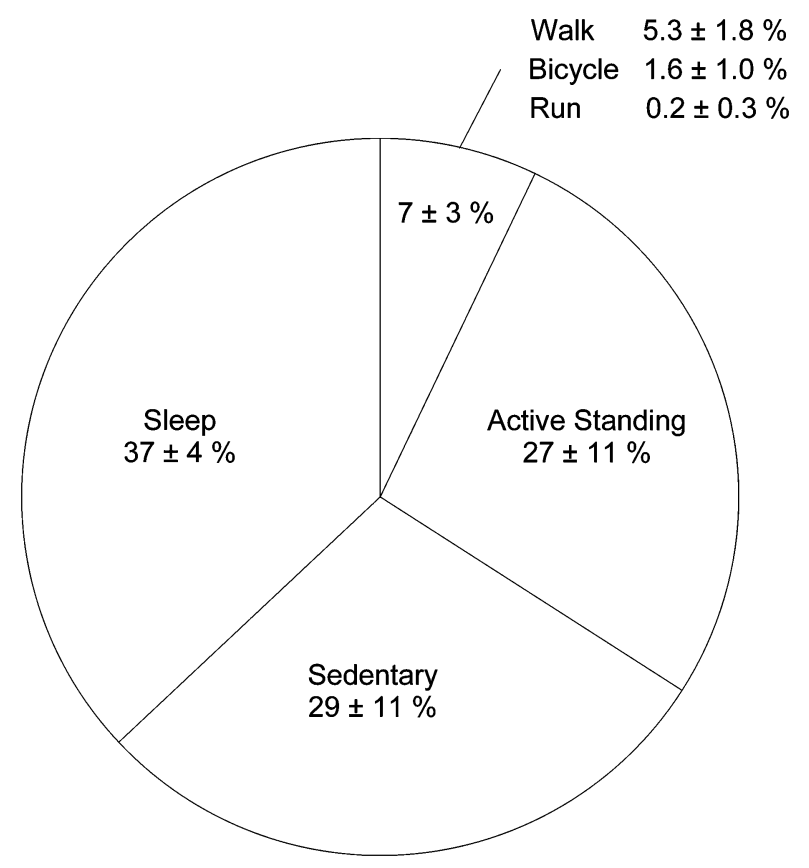

Fig. 2. Daily distribution of the types of activity characterizing the individuals' behaviors. Percentage values represent the proportion of the $24 \mathrm{~h}$ day spent on each activity type. Sedentary, sum of lying, sitting, and standing still during waking hours; AS, active standing. that the characteristics of the PA behavior that mainly determined the PAL were the sedentary time and the activities related to transportation such as walking and bicycling. In particular, the sedentary time negatively affected the PAL, while walking and bicycling played a determinant role in increasing the PAL. Sleeping appeared not to be associated with PAL. Generic standing activities such as household tasks were significantly associated with PAL. In addition, the high negative co-linearity observed between the daily duration of active standing and sedentary behavior provides evidence of a complementary nature between these two characteristics of activity behavior. This was also observed in a study of Healy et al. (2008), where the objectively measured time spent in light-intensity activities was inversely related with the time spent being sedentary. The time spent running was positively associated with the PAL but the relation just failed to reach significance $(P=0.06)$.

The innovative methodology used to monitor PA, based on one accelerometer and a classification algorithm, was used to objectively determine the engagement in different types of activities. Six activity classes were considered and they were selected to represent common types of daily PA. The lying,

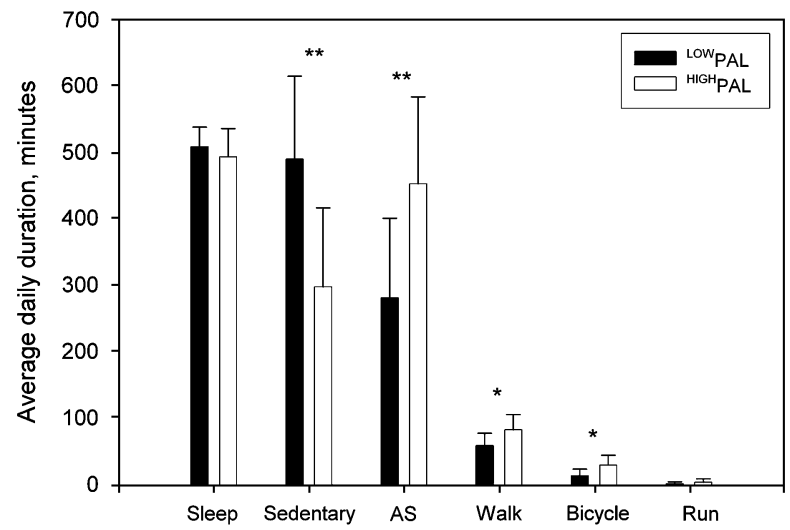

Fig. 3. Differences in the engagement in the types of activity characterizing the behavior of subjects belonging to the LOW PAL group (PAL < 1.75) compared with that of the ${ }^{\mathrm{HIGH}} \mathrm{PAL}$ group (PAL $\left.>1.75\right)$. AS; active standing. $* * P<0.01$. ${ }^{*} P<0.02$. PAL, physical activity level.

Table 2. Average daily duration of each activity type and their correlation with the physical activity level (PAL)

\begin{tabular}{lccll}
\hline min/day & Mean \pm SD & Range & Correlation vs PAL \\
\hline Sleep & $501.2 \pm 36.3$ & $429.3-548.6$ & $R=-0.12$ & $P=0.61$ \\
Sedentary & $393.2 \pm 154.6$ & $84.1-663.9$ & $R=-0.72$ & $P<0.001$ \\
Active standing & $367.4 \pm 150.4$ & $138.4-678.6$ & $R=0.62$ & $P<0.01$ \\
Walk & $71.5 \pm 23.6$ & $29.0-117.1$ & $R=0.49$ & $P<0.05$ \\
Bicycle & $22.1 \pm 14.6$ & $3.5-56.5$ & $R=0.77$ & $P<0.001$ \\
Run & $3.2 \pm 4.3$ & $0-14.3$ & $R=0.43$ & $P=0.06$
\end{tabular}

Sedentary, sedentary behavior: Iying, sitting and standing still; $R$, Pearson' correlation coefficient; $P$, significance level. 
Table 3. Physical activity level (PAL) model developed using the stepwise multiple-linear regression algorithm

\begin{tabular}{llccc}
\hline Dependent & Independent & Coefficient & Partial $R^{2}(\%)$ & $P$ \\
\hline PAL & Intercept & 1.655 & & \\
& Bicycle & 0.0053 & +59 & $<0.01$ \\
& Walk & 0.00205 & +9 & $<0.05$ \\
& Sedentary & -0.000385 & +7 & $<0.05$
\end{tabular}

Dependent, dependent variable; Independent, independent variable; Partial $R^{2}$, increase in the explained variance of the model; $P$, significance level of the increased $R^{2}$.

sitting, and standing classes were defined to represent static postures. The walking and running classes were defined to represent gait and ambulation. The active standing class was defined to represent human movements performed in the standing position not related to ambulation. Additionally, the bicycling class was considered as bicycling is not only engaged in for sport practice, but mainly for transportation purposes. In fact, in the Netherlands, bicycling is the favorite means of transport for trips up to $7.5 \mathrm{~km}$ (Rietveld \& Daniel, 2004). This represented a unique feature of the used accelerometer, as many commercial devices measure PA irrespectively of the type of activity performed, resulting in inaccurate estimations of the amount of PA scored during certain activities such as bicycling.

Only few other studies have objectively measured the duration of different types of activities in daily life in combination with DLW measures of PAL. Johannsen et al. (2008) monitored PA in a population of lean adult women for 4 days, using the intelligent device for energy expenditure and physical activity (IDEEA). Compared with our results, sitting and standing had a longer daily duration [890 vs $760 \mathrm{~min} /$ day; (sedentary+active standing)], and the engagement in walking, running, and stepping was shorter [48 vs $75 \mathrm{~min} /$ day; (walk + run)]. This difference cannot be explained by a different activity level of the two study populations. Indeed, the average PAL measured over a period of 14 days was similar to the average value obtained in the current study. Thus, a possible explanation of the differences in PA behavior could be found by considering the different measurement systems used. Possibly, the PA recorded using IDEEA could have been biased toward a more sedentary behavior. The limited wearability of IDEEA, which consists of five accelerometers connected by wires, compared with Tracmor could result in an increased burden on the subjects and this might have discouraged their engagement in normal PA. Harris et al. (2007) using the PAMS activity monitor measured, posture and allocation in adult young and elderly subjects. The adult young population was lying for $530 \mathrm{~min} /$ day, was sitting for
$426 \mathrm{~min} /$ day, and was standing (still or actively) for $500 \mathrm{~min} /$ day, on average. These values are in agreement with the findings of our study, where the active standing, walking, bicycling, and running duration (464 min/day) is considered to represent the standing class of Harris et al. The PAL of the study population as measured using DLW was 1.73; hence, the correspondence in PA behavior is confirmed by this similarity in PAL.

PA represents one of the main components of daily energy expenditure (Westerterp, 2008). Genetic and environmental factors contribute to explain the interindividual variability in PA (Joosen et al., 2005). The current study showed that some aspects of PA behavior determined the PAL. Locomotion and transportation activities such as walking and bicycling were positively associated with PAL. Sedentary time affected the mean PAL negatively. This implies that an efficient way to increase the activity level is to engage in more physically active transport, spend relatively more time walking and bicycling, and reduce the amount of time spent in sedentary behaviors at work, at home, and during leisure-time. These findings are in line with the evidence suggesting that contemporary changes in transport, occupations, domestic tasks, and leisure activities have had negative effects on the activity level. According to the multiple-linear regression model, replacing daily 30 min of sedentary time with walking increases the PAL by 0.07 , which represents about $5 \%$ of the average PAL $(=1.75)$, while $30 \mathrm{~min} /$ day of bicycling instead of sitting in a car would result in twice the increase in PAL, i.e. $10 \%$ of the average PAL. Achieving a PAL of 1.75 , given that the walking and bicycling duration is equal to the average duration registered in this study, requires to limit the sedentary behavior to $7.5 \mathrm{~h} /$ day. This could be achieved, for instance, by developing specific strategies to interrupt prolonged sitting time with active breaks (Owen et al., 2009). It would be helpful not only to achieve a higher activity level but also to reduce the risk for cardiovascular diseases (Weller \& Corey, 1998), metabolic syndrome (Dunstan et al., 2005), weight gain (Levine et al., 2008), and all causes of mortality (Matthews et al., 2007). Indeed, epidemiological evidence has shown a positive relationship between certain patterns of inactivity, disease outcomes, and mortality risk (Hamilton et al., 2007). Moreover, intervention studies have recently identified specific cellular mechanisms, activated during the contractile activity of postural skeletal muscle, involved in the regulation of risk factors for disease (Bey \& Hamilton, 2003). Therefore, intermittent activities during prolonged sedentary time could be considered as a functional strategy for increasing energy expenditure and improving health by stimulating physiological effects generated by muscle con- 


\section{Bonomi et al.}

traction during low-intensity activities (Hamilton et al., 2007).

We recognize limitations in this study. Firstly, it could be argued that the number of days considered for the assessment of the PA pattern was, on average, small. However, some studies showed that 3-4 days of monitoring were sufficient to achieve a reliability of $>80 \%$ in measurements of PA using accelerometers (Levin et al., 1999; Matthews et al., 2002). Therefore, measuring PA for an average of 8 consecutive days, as in the current study, seems reasonable for a reliable assessment of the habitual PA. Secondly, errors in the identification of activity type could determine incorrect assessment of the $\mathrm{AD}_{\mathrm{D}}$ of the different activities. However, the classification model showed high classification performances, and classification errors were infrequent. Another limitation of this study might be the reduced number of subjects included. However, the study population was carefully selected to be characterized by a broad BMI range. Moreover, the participants covered the range of normal daily-life activity levels, as indicated by the measured PAL range, which was $1.43-2.08$, but were not highly physically active. Indeed, a PAL of 1.43 indicates sedentary lifestyles (Black et al., 1996), a PAL of 2.08 represents more active lifestyles (Westerterp, 2001), and highly active lifestyles are characterized by PAL of 2.5 (Black et al., 1996).

\section{Perspectives}

In a group of healthy Dutch subjects, there is objective evidence indicating that sedentary time and activities related to transportation and commuting, such as walking and bicycling, significantly determine the average PAL. Efficient strategies to increase the activity level may target these aspects of the individuals' activity behavior to promote PA and the associated health benefits.

Key words: activity monitoring, physical activity recommendations, activity recognition, locomotion.

\section{Acknowledgement}

This work was funded by Philips Research.

\section{References}

Bey L, Hamilton MT. Suppression of skeletal muscle lipoprotein lipase activity during physical inactivity: a molecular reason to maintain daily low-intensity activity. J Physiol 2003: 551: 673-682.

Black AE, Coward WA, Cole TJ, Prentice AM. Human energy expenditure in affluent societies: an analysis of 574 doubly-labelled water measurements. Eur J Clin Nutr 1996: 50: 72-92.

Blair SN, Cheng Y, Holder JS. Is physical activity or physical fitness more important in defining health benefits? Med Sci Sports Exerc 2001: 33: S379S399.

Bonomi AG, Goris AH, Yin B, Westerterp KR. Detection of type, duration, and intensity of physical activity using an accelerometer. Med Sci Sports Exerc 2009a: 41: 1770-1777.

Bonomi AG, Plasqui G, Goris AH, Westerterp KR. Improving assessment of daily energy expenditure by identifying types of physical activity with a single accelerometer. J Appl Physiol 2009b: 107: 655-661.

Dietz WH. The role of lifestyle in health: the epidemiology and consequences of inactivity. Proc Nutr Soc 1996: 55: 829840.

Duda RO, Hart PE, Stork DG. Pattern classification, 2nd edn. New York: Wiley-Interscience, 2000.
Dunstan DW, Salmon J, Owen N, Armstrong T, Zimmet PZ, Welborn TA, Cameron AJ, Dwyer T, Jolley D, Shaw JE. Associations of TV viewing and physical activity with the metabolic syndrome in Australian adults. Diabetologia 2005: 48: 2254-2261.

Ekelund U, Brage S, Besson H, Sharp S, Wareham NJ. Time spent being sedentary and weight gain in healthy adults: reverse or bidirectional causality? Am J Clin Nutr 2008: 88: 612-617.

Epstein LH, Roemmich JN. Reducing sedentary behavior: role in modifying physical activity. Exerc Sport Sci Rev 2001: 29: 103-108.

Ermes M, Parkka J, Mantyjarvi J, Korhonen I. Detection of daily activities and sports with wearable sensors in controlled and uncontrolled conditions. IEEE Trans Inf Technol Biomed 2008: 12: 20-26.

Hamilton MT, Hamilton DG, Zderic TW. Role of low energy expenditure and sitting in obesity, metabolic syndrome, type 2 diabetes, and cardiovascular disease. Diabetes 2007: 56: 2655-2667.

Harris AM, Lanningham-Foster LM, McCrady SK, Levine JA. Nonexercise movement in elderly compared with young people. Am J Physiol -
Endocrinology and Metabolism 2007: 292: E1207-E1212.

Haskell WL, Lee IM, Pate RR, Powell KE, Blair SN, Franklin BA, Macera CA, Heath GW, Thompson PD, Bauman A. Physical activity and public health: updated recommendation for adults from the American College of Sports Medicine and the American Heart Association. Med. Sci. Sports Exerc 2007: 39: 1423-1434.

Healy GN, Wijndaele K, Dunstan DW, Shaw JE, Salmon J, Zimmet PZ, Owen N. Objectively measured sedentary time, physical activity, and metabolic risk: the Australian Diabetes, Obesity and Lifestyle Study (AusDiab). Diabetes Care 2008: 31: 369-371.

Hu FB, Li TY, Colditz GA, Willett WC, Manson JE. Television watching and other sedentary behaviors in relation to risk of obesity and type 2 diabetes mellitus in women. JAMA 2003: 289: 1785-1791.

Johannsen DL, Welk GJ, Sharp RL, Flakoll PJ. Differences in daily energy expenditure in lean and obese women: the role of posture allocation. Obesity 2008: 16: 34-39.

Joosen A, Gielen M, Vlietinck R, Westerterp KR. Genetic analysis of physical activity in twins. Am J Clin Nutr 2005: 82: 1253-1259. 
Behavior and activity level

Karantonis DM, Narayanan MR, Mathie M, Lovell NH, Celler BG. Implementation of a real-time human movement classifier using a triaxial accelerometer for ambulatory monitoring. IEEE Trans Inf Technol Biomed 2006: 10: 156-167.

Kesaniemi YA, Danforth E, Jensen MD, Kopelman PG, Lefebvre P, Reeder BA. Dose-response issues concerning physical activity and health: an evidence-based symposium. Med Sci Sports Exerc 2001: 33: S351-S358.

Kriska AM, Saremi A, Hanson RL, Bennett PH, Kobes S, Williams DE, Knowler WC. Physical activity, obesity, and the incidence of type 2 diabetes in a high-risk population. Am J Epidemiol 2003: 158: 669-675.

Levin S, Jacobs DR, Ainsworth BE, Richardson MT, Leon AS. Intraindividual variation and estimates of usual physical activity. Ann Epidemiol 1999: 9: 481-488.

Levine JA, McCrady SK, LanninghamFoster LM, Kane PH, Foster RC, Manohar CU. The role of free-living daily walking in human weight gain and obesity. Diabetes 2008: 57: 548-554.

Macfarlane DJ, Lee CCY, Ho EYK, Chan KL, Chan D. Convergent validity of six methods to assess physical activity in daily life. J Appl Physiol 2006: 101: 1328-1334.

Mathie MJ, Celler BG, Lovell NH, Coster ACF. Classification of basic daily movements using a triaxial accelerometer. Med Biol Eng Comput 2004: 42: 679-687.

Matthews CE, Ainsworth BE, Thompson RW, Bassett DR. Sources of variance in daily physical activity levels as measured by an accelerometer. Med Sci Sports Exerc 2002: 34: 1376-1381.

Matthews CE, Jurj AL, Shu XO, Li HL, Yang G, Li Q, Gao YT, Zheng W. Influence of exercise, walking, cycling, and overall nonexercise physical activity on mortality in Chinese women. Am J Epidemiol 2007: 165: 1343-1350.

Meijer EP, Westerterp KR, Verstappen FT. Effect of exercise training on total daily physical activity in elderly humans. Eur J Appl Physiol Occup Physiol 1999: 80: 16-21.

Owen N, Bauman A, Brown W. Too much sitting: a novel and important predictor of chronic disease risk? Br J Sports Med 2009: 43: 81-83.

Pate RR, Pratt M, Blair SN, Haskell WL, Macera CA, Bouchard C, Buchner D, Ettinger W, Heath GW, King AC, Kriska A, Leon AS, Marcus BH, Morris J, Paffenbarger RS, Patrick K, Pollock ML, Rippe JM, Sallis J, Wilmore JH. Physical activity and public health. A recommendation from the Centers for Disease Control and Prevention and the American College of Sport Medicine. JAMA - J Am Med Assoc 1995: 273: 402-407.

Plasqui G, Joosen A, Kester AD, Goris AHC, Westerterp K. Measuring freeliving energy expenditure and physical activity with triaxial accelerometry. Obesity Res 2005: 13: 1363-1369.

Pober DM, Staudenmayer J, Raphael C, Freedson PS. Development of novel techniques to classify physical activity mode using accelerometers. Med Sci Sports Exerc 2006: 38: 1626-1634.

Preece SJ, Goulermas JY, Kenney LP, Howard D, Meijer K, Crompton R. Activity identification using bodymounted sensors - a review of classification techniques. Physiol Meas 2009: 30: R1-R33.

Rietveld P, Daniel V. Determinants of bicycle use: do municipal policies matter? Transp Res Part A - Policy Pract 2004: 38: 531-550.

Schoffelen PFM, Westerterp KR, Saris WHM, TenHoor F. A dual-respiration chamber system with automated calibration. J Appl Physiol 1997: 83: 2064-2072.

Veltink PH, Bussmann HB, de Vries W, Martens WL, Van Lummel RC. Detection of static and dynamic activities using uniaxial accelerometers. IEEE Trans Rehabil Eng 1996: 4: 375 385.

Weir JBD. New methods for calculating metabolic rate with special reference to protein metabolism. Journal of Physiology-London 1949: 109: 1-9.

Weller I, Corey P. The impact of excluding non-leisure energy expenditure on the relation between physical activity and mortality in women. Epidemiology (Cambridge, MA) 1998: 9: 632-635.

Westerterp KR. Pattern and intensity of physical activity. Nature 2001: 410: 539-539.

Westerterp KR, Wouters L, Lichtenbelt WDV. The Maastricht protocol for the measurements of body composition and energy expenditure with labeled water. Obesity Research 1995: 3: 49-57.

Westerterp KR. Physical activity as determinant of daily energy expenditure. Physiol Behav 2008: 93: 1039-1043.

Zhang K, Werner P, Sun M, Pi-Sunyer FX, Boozer CN. Measurement of human daily physical activity. Obesity Research 2003: 11: 33-40. 